\title{
Librarians' Online Efforts Toward Virtual and Collaborative Information Services
}

\section{Dr. Michelle Kowalsky}

Rowan University, NJ USA

\section{Doi:10.5901/jesr.2013.v3n7p100}

\begin{abstract}
Virtual worlds have attracted hundreds of librarian volunteers who are interested in exploring virtual online environments like Second Life (R) as avenues to deliver and promote library resources to users "where they are." A core team of leaders from a variety of library types from many countries emerged online during this initiative to tackle many difficult questions in developing and implementing library services for virtual users. As innovators, librarians are not often seen as leaders by those outside of the profession. However, a growing online presence of librarians as technological early adopters has emerged to inform our view of ways in which library and information services professionals can design, test, and revise online "third places" where social interaction, information exchange, and inquiry about technologies or any other topics can occur as seamlessly as in a physical library. Online virtual environments have been truly social learning environments for the librarians, as well as for their users. We need to not overlook the importance of these new spaces or "sandboxes" as most useful for professional development of instructors and information professionals. Transferable skills in online collaboration, articulating oneself clearly through words and avatars, and functioning as a contributing team member on a new and uncharted initiative are truly valuable experiences for professional learning in information, communication, and technology (ICT) fields.
\end{abstract}

\section{Introduction}

\begin{abstract}
Many librarians are concerned about the future. They worry that the library may fade away or become unimportant and that their own roles may shrink. These anxieties are realistic only if librarians are unavoidably dependent on the library as a physical place. The history of librarianship in the twentieth century demonstrates that they are not. Librarians met the initial challenges of the computer revolution reasonably and with a noteworthy series of successes. These were driven by the propensity of librarians to work cooperatively with others at local, regional, national, and international levels and by their inclination to share what they know. As a result, librarians can look to the Twenty-first Century with excitement and anticipation. No longer are they the custodians; rather they are the guardians with the capacity to shape their own environments for the benefit of their clients. (Martell, 2003, p. 2524)
\end{abstract}

With the dawn of the digital age, librarians began to seek new ways to store and organize information, to provide access to that information for patrons, and to provide new methods of awareness and communication for the general public about what libraries have to offer. Over time, libraries automated their catalog of book and periodical holdings for easier searching via computer, significant innovations for a traditional profession in a relatively short period of time. Now librarians are utilizing social computing tools to not only make library information available for free via interactive web pages and multimedia web portals, but also to communicate with library users and each other online. Sharing resources, asking and answering questions, connecting people to information, and engaging others in discussion of this new information have become important and valued services provided by libraries of many kinds.

Libraries began to embrace new technologies initially so that they could more easily and appropriately accomplish their goals of providing information and sharing knowledge freely and widely. Text-only library catalog searches began to include hyperlinks, graphics, and interconnected holdings information from libraries around the country and around the world. Libraries used increasingly sophisticated websites, which often included blogs and news feeds to provide users with updated electronic information quickly and via the most authoritative sources available. Librarians began to rely on online social networks to facilitate resource sharing among institutions, as well as to provide support for answering patron's reference questions by relying on each other for subject expertise.

In recognition of the importance of technology for the work of libraries and society everywhere, members of the American Library Association (ALA) -- the national professional organization of librarians in the United States articulated a series of strategic steps to better fulfill the needs of tech-savvy users. In espousing the mission of promoting the availability and usability of information tools and technologies which meet the changing needs of its users and society, they have helped incorporate innovation and transformation into its mission and strategic plans for libraries 
everywhere. Specifically, ALA has committed to "providing leadership in the transformation of libraries and library services in a dynamic and increasingly global digital information environment;" to increase sharing, assistance, and recognition for "experimentation with innovative and transformational ideas;" and to "help libraries make use of new and emerging technologies" through promotion, training and support of innovative ideas which help others connect to information and each other as they learn ("ALA 2015 Strategic Plan," 2010, p. 5).

Clearly, the social computing expectations of library users have continued to rise just as much as those in the private sectors, thus demanding even more sophistication from libraries and their librarians for free and easily accessible information, modern technological tools and training to use them, and personal assistance for help with research, current awareness, and decision-making.

\section{Promoting Learning in Multi-User Online Environments}

In order to keep current with all of this communication and information technology, librarians themselves needed to embark on a consistent and somewhat aggressive professional development sequence over the last few decades. New technologies were developed and piloted, often in concert with information technology specialists and software vendors. Staff members were trained, and they in turn helped library users learn the new technologies. With the goal of providing services to users in the format they not only needed but expected, librarians developed various electronic standards, methods, and procedures for storing, accessing and sharing information via the Internet. Conferences, workshops, journals and discussion groups about technology ensued and became increasingly online enterprises in developing learning communities among information professionals. Perhaps ironically, librarians soon became known for their technology expertise in addition to their "book smarts." But in a technological environment in which many sources professed authority, accuracy, and helpfulness, libraries had to assert their worth as trusted sites from which (and from whom) to learn.

The library has been -- as it could not be otherwise since it is involved in the field of communication -- one of the first institutions that has benefited from an active online presence. The importance of that presence is growing, since many have [heretofore] equated an organization's lack of an online presence with nonexistence. (Alonso Arévalo, 2002, p. 6)

Libraries today continue to strive to meet their users "where they are," whether in our local communities or online in cyberspace. Librarians have made a concerted effort to improve the functionality and social capacity of their online information portals, making them similar to the sophisticated styles that users now expect to encounter when browsing commercial sites on the Web. Many libraries have also integrated a variety of Web 2.0 tools such as wikis, RSS feeds, user rankings, tagging, embedded or streaming video, and live chat functions, which many web users view as a hallmark of modernity. Virtual reference applications, which allow users and librarians to chat and co-browse the web synchronously and experience virtual world interactions are beginning to meet the needs of users who need or prefer to have these interactions online rather than in-person. Most importantly, however, is the ability of libraries to explore and implement these new technologies successfully, while functioning on shoestring budgets and by relying on an in-house tech-savvy spirit of adventure as they create, modify, and build applications which rival those of corporate peers.

Abram (2006) noted that the Web 2.0 conversation is "primarily about a much higher level of interactivity and deeper user experiences, which are enabled by the recent advances in Web software combined with insights into the transformational aspects of the Internet" (\$ 7). This is echoed again years later in the recommendations of Bi-xia (2010), who encourages a blend of technologies to not only serve users better but to also improve librarian competencies. The continual theme throughout the literature is encouraging librarians to innovate with the most promising technologies to improve user experiences, not just to try random innovations without specific advances in mind.

When considering library technology innovation, Abram also reflects both the interests and concerns of modern libraries when he concludes that "Web 2.0 is ultimately about a social phenomenon -- not just about networked social experiences but about the distribution and creation of Web content itself," in which users of all kinds, including library patrons and staff, come together in a more open conversation about content (Abram, 2006, I 7). Stevanović and Crnogorac (2011) similarly call for a balance between cutting-edge innovation and traditional approaches to serving users and echoing the term "harmony" to describe ways to effectively integrate technologies with current user services. This movement has clearly morphed into daily web-centric activity that has become not just about content but also about authority, reliability, timeliness as much as it is about connections, exchanges and discussions -- in essence, about information discovered and shared, and what was learned in the process.

In a socially and technologically connected world, libraries are therefore just one of many creators and distributors 
of information; audience participation via the Internet changed many of the traditional paradigms of information services in which libraries were the repository of all information that was valuable. Users wanted what they wanted, when they wanted it, and in the format of their choosing, and by extension, many libraries felt that library services now needed to be provided in ways that were compatible with the social computing practices of everyday life. In an increasingly rich and complex information environment, librarians continue to help users navigate, participate, and critically analyze the claims and data they have found online, and to connect them with experts and knowledgeable assistance at the time and point of need, however mobile or urgent. For those who want to question or verify what they find easily and quickly online, and for those who have already realized that information often accompanies intent, librarians are providing the value-added service of helping users question what they see, hear, and consume from pervasive media outlets and online search tools.

The emergence of new demands surrounding information and its delivery and deliberation naturally dictates the need for libraries to meet these emerging user interests and desires, and to create a newer, more participatory type of user interaction. According to a recent major survey in the library community, "libraries, many of their resources and services, and the information experts who work in libraries appeared to be increasingly less visible to today's information consumer" (OCLC, 2005, p. 1). A combination of both hope and strategy from all types of library professionals thus aims to position the information services of libraries squarely within the field of vision of techno-savvy $21^{\text {st }}$ Century citizens.

As multi-user online environments such as virtual worlds expanded, the field began to study the new network phenomena of "one- to-many" and "many-to-many" communication afforded by a more visual and increasingly networked online medium. Online spaces began to offer images and other graphical vistas in addition to text, which could be both exchanged and viewed by simultaneous users. Some even recreated physical libraries in virtual settings, replete with great books, rotating literature displays, and all of the time-sensitive news and announcement functions one would expect. This new medium brought with it possibilities limited only by the librarians' and users' imaginations.

In this new three-dimensional environment, where multiple users could interact with online items and with each other, Second Life ${ }^{\circledR}$ users began to learn to design, or script, new objects. Through open architecture of its software's design code, anyone could build a tree, a car, or a vacation home in-world. For many, living another virtual life online became an escape from the pressures of real life, or a fantasy world to try out new ideas or personas. For a relatively "traditional" profession, virtuality became an intriguing method of dispelling stereotypes and a variety of online behaviors, some similar and some quite unlike those in the real world, became the norm. As Turkle (2005) explained, professionals and educators could live out their "life on the screen," assuming a cartoon-like identity of their own design and even a new name to go along with it. Through open architecture of its software's design code, anyone could build items or structures or landforms, and that remains one of the attractions of Second Life $₫$ to date. The theories of participatory design and participatory culture on the Internet have led ordinary users to both design and develop online projects that surpass previous efforts in scale, size, complexity, use and popularity. Yet not everyone was enamored with virtual environments as places to do serious inquiry or investigation.

\section{Implications for Libraries in Virtual Worlds and Beyond}

Some critics of virtual worlds maintain that the highly customizable environment of Second Life $₫$ "is typified in the media as an over-populated, lawless land, easily obliterated by its owners ... [and is] rapidly devolving into 'Second Strife" (Cheal, 2007, p. 205). This assertion was hotly debated in the literature during the librarians' first year of conversations about pioneering efforts in virtual spaces. Proponents of both sides of a seemingly black-and-white argument carried out their attacks and defenses of the service in numerous professional blogs and online forums, and subsequently in professional journals. Many aspects of online society seem to trump the perceived dangers and possible troubles of life conducted over the Internet. The "social aspect" and "sense of togetherness" which seemed to be valued qualities of these and other online virtual environments could not be denied.

Yet as Cheal (2007) continued to explain, "we can hold up a virtual world to our own to better reflect and magnify the important issues in our real world" (p. 205). In a ubiquitous online learning environment, we may be able to improve on the real world, replicate it, or ignore elements in order to focus on a new mode of communication (Huancheng \& Miaolei, 2011). The debate over whether Second Life® was inherently good or bad for the librarians, or whether it was useful for libraries, was truly a discussion of none of these points. What was in question may have been society's readiness (or lack thereof) to participate in an online world as chaotic as the real one, and therefore, the library profession's choice to join in the purported mayhem.

At the end of a first year of online discussion about their virtual world efforts by 650 early-adopter librarians and 
educators of the Alliance Library Group of Illinois, firm conclusions about virtual world efforts were not yet drawn by participants. Utility of the platform for library service, and conclusions or analysis of its limitations did not appear to be negative enough to discontinue the project (Alliance Library System, 2008). The librarians worked out among themselves what to do in a new virtual world, how to do it, and who would do it. Yet, this do-it-yourself system didn't work for everyone involved. Some participants explained that the workload and emergent organization was difficult to deal with, and ultimately led to hard feelings and decisions to leave an otherwise enjoyable initiative. Overall, it appears that the participants collectively kept an open mind about the potential of virtual worlds as vehicles for expanding libraries' reach and improving users' understanding of what help and resources could be available to them.

The Alliance Second Life ${ }^{\circ}$ Library participants have been shown to be a group of interested and forward-thinking professionals, mostly volunteers who chose to embark on a surely ambiguous and potentially overwhelming initiative with uncertain outcomes. And, it appears, they did not do so blindly. Periodic large-group reflective discussions, as well as numerous interpersonal conversations, showed clearly that the librarians tried to analyze their own moves and those of the larger group. Subgroups which formed to work on specific aspects of library services, such as those interested in health information, teens, or Nineteenth Century themes, flowed freely to and from the larger group, reporting back to the group leader and other prolific participants periodically.

As a result, the librarian participants themselves experienced an intense and engaging professional development activity through participation in the initiative. As the participants in this group learned from each other, they explored many of the emerging issues of an increasingly online existence. As many have noted in the literature, this work broke new ground in investigating user services and possibilities for future interactions among those seeking and sharing information. Librarians who had not previously engaged in multi-user virtual environments, played video games, or worked on a multinational or distance-led collaborative effort were now immersed in a new world which holds much potential for serving users in new and innovative ways.

Second Life® thus provided the librarians with a workable, fully customizable and operational environment to explore the potential of providing library services to online users in a relatively new format. Although criticized for forging into this seemingly "bleeding edge" technology with such numbers and commitment early in the platform's existence, the librarians in the group -- and the profession at large -- appeared to meet these challenges with grace and optimism. Their online discussions consistently show reflection on both the new medium and the new presence of librarians in it, similar to results from Buckland and Godfrey (2008). The decision to explore Second Life® with such gusto does not appear to have been taken lightly, and the new knowledge gained, appears to have informed the profession on many levels.

Similarly, explicit acknowledgement of the opportunities of the emerging medium and a close relationship with Linden Lab, the creators of the Second Life® environment, has benefitted the librarians' development. 'We included '2.0' in the SLL project name because we wanted to implement and build upon some of the excellent ideas and principles emanating from the Library 2.0 movement," and since then "the Alliance Second Life® Library 2.0 has evolved into Library 3D, as it has moved quickly beyond text and graphics" (Trueman, Peters, \& Bell, 2007, p. 160). Even through the first year of the project's existence, the Library 2.0 movement progressed itself, and began to give way to more immersive virtual experiences as possibilities for library instruction, operation, and outreach. But many barriers still exist between library professionals, who are often proponents of the "information wants to be free" movement, and vendors who must turn a profit on partnerships which have the potential to influence current trends.

The Second Life® librarians seem to have utilized all of the strengths of an emerging 3-D web-based environment. Spaces are provided for conversation, building of new creations, or interactions with others' creations. Images of their innovative 3-D objects and services abound, and were often shared by the librarians with each other, via conference presentations which become records of their online efforts in various media. And so it seems, librarians from a variety of information organizations have figured out ways to appropriate the opportunities of a virtual space for their particular niches, all in the service of the greater mission and goals of libraries -- to connect people with the information they need and desire, wherever they may be. However, just as quickly as they developed a presence in the virtual arena, public interest has shifted toward other tools and applications. Nevertheless, lessons learned in these efforts will certainly appear to inform, but not hinder, the subsequent forays of librarians into new technological movements.

\section{Social Computing as Learning for Librarians}

The online world of the Second Lifeß librarians, which involved participants from all types of libraries and with varying levels of commitment to the project, was not eternally rosy. Several challenges and issues remained as popular topics 
throughout the first year of conversation and beyond. For example, discussions of whether replicating the real-world feel of libraries or conversely embarking on some futuristic idea of library service in a persistent virtual environment was a frequent yet inconclusive topic. Authors began to write and cite outside of the discussion group about these difficulties. As participants are "confronted with the notion that sometimes our 'virtual' spaces leak over into our 'real' worlds, and the nature of concepts like ownership in shared multiuser space are not a given" (Taylor, 2006, p. 151), the project appears to take on a life of its own. The many-to-many communication concept begins to involve outside users and outside builders in periods of exponential growth. "Examining the collective construction of culture -- which, it must be said, turns on constant acts of reappropriation by all parties -- introduces useful provocations for analysis" (Taylor, 2006, p. 150).

As the repurposing of objects, conversations, ideas and analysis occurred for these librarians, thus indeed building an internal culture among participants in their discussions and simultaneously an immersive library world for their constituents, several views of the project collided, both among participants and between the virtual world and the real world. The librarians periodically struggled with these issues, content to hold in mind the inherent competing tensions of the ideas until further exploration was performed and additional discussions took place.

As evidenced above, the librarians during their first year struggled with issues of the real versus the virtual, a predictable developmental process for those investigating a new medium and its opportunities. The librarians, as well as their users, needed to wrestle with a strange new set of rules and possibilities. In a persistent virtual world, "all of the higher order knowledge skills from Bloom's taxonomy are possible -- applying knowledge (e.g., moving about in Second Life $囚$ ), analyzing (How can I build something realistic with a low prim count?), evaluating (Is it best to build a cathedral ceiling to show support systems or to leave it off to allow avatars to fly in?), and creating (use SL building skills to build a complete cathedral. Bloom's learning characteristics correlate well with the exploration and interaction inherent in virtual worlds" (Cheal, 2007, p. 208).

As part of their steep learning curve, the librarians constantly needed to reference their real world service sites and background knowledge of brick-and-mortar libraries, and begin to integrate new knowledge in the field such as best practices in digital reference services. However, as the librarians showed in this study, they did not pass group judgment on the initiative too early. They built libraries in-world which both resembled and were totally different from their counterparts in real life. "And is there any danger in too much 'real world' seeping in? Keeping the real world out is not the battle to be won or lost. We do not shed culture when we go online and enter game worlds, nor do designers create these incredible spaces in a vacuum. And this is a good thing. Culture is what we are and what we do, and understanding the varying ways all participants are productive is one of our best tools in making sense of what emerges" (Taylor, 2006, p. 154). The librarians' developmental processes showed that at times they suspended disbelief, as well as held contradictory information and feedback in mind simultaneously. Indeed, their exponential growth in numbers and communicative events was encouraged by the distinct lack of a black-and-white view of libraries and of themselves.

However, current stereotypes and several negative images of libraries in Second Life® still appeared, not only in other online forums but also their own professional literature. For example, an early article in School Library Journal, a top publication in the library field, otherwise positively describes the initial book club efforts of the Alliance Library System in Second Life®. The publication, however, began with the sentence, "If patrons won't come to the library, librarians are willing to take the institution to their customers -- even if that means traversing through cyberspace into the virtual world" (Barack, 2006, p. 26). This continual reinforcement of diminished value of libraries in the eyes of patrons presents an unending and repopulating cycle which helps old ideas about libraries to persist even in quite different and modern environments. Unfortunately, librarians themselves perpetuate these connotations -- unintended or inadvertent or subliminal disparagements -- presumably to connect with non-librarian readers who may be attracted and then influenced why what is read, or to engage a wider audience who may already believe that libraries are warehouses of the past. Librarians are also encouraged by their own journals to keep a portfolio of their intellectual work to justify their efforts (Marks, 2013). Until our profession can successfully negotiate these issues of image, we may never fully progress in the eyes of the users who we so desperately need in order to exist.

Online virtual environments have been truly social learning environments for the librarians, if not for their users. We need to not overlook the importance of these new spaces as having uses for professional development with those doing the teaching and not necessarily for those taught. Studies of the choices made by librarians as they create public 3-D versions of themselves, or similarly of their views of future incarnations of digital representations of library professionals, are rich in information about the evolution of the profession over time (and the degrees of its evolutionary successes) as well as characteristics of early-adopter technologically-minded librarians. Studies which expand our understanding of librarianship in a variety of ways, and which are influenced by a variety of theoretical frameworks and draw inspiration from a variety of subject areas, would faithfully reflect the same diversity found in this field's scholars and 
practitioners.

From a variety of viewpoints, research on the technological work of, by, and between librarians will help to inform an information literate society, as well as to improve the lives of those who may most benefit from its democratic mission. In fact, this work is necessary not simply to keep the library profession alive, but to help improve society in meaningful ways which can be designed and provided specifically by information professionals of all types. As long as information is at the heart of a society's infrastructure, technological means will continue to be required to make it salient and valuable for a society of learners. Whether that information continues to be valued by society is up to the librarian professionals who assist in its creation and use.

\section{References}

Abram, S. (2006). Web 2.0, library 2.0, and librarian 2.0: Preparing for the 2.0 world. Retrieved March 26, 2008, from http://www.imakenews.com/sirsi/e article000505688.cfm

Alliance Library System. (2008). Retrieved March 11, 2008 from http://www.alliancelibrarysystem.com/about/mission.cfm

Alonso Arévalo, J. (2002). InfoDOC: Lista de distribución de información sobre

biblioteconomía y documentación. Proceedings encontro de bibliotecarios, Gguarda (Portugal). Retrieved February 12, 2008, from http://eprints.rclis.org/ archive/ 00003424/01/infodoc.pdf

American Library Association (ALA) 2015 Strategic Plan. Retrieved April 25, 2013, from http://www.ala.org/ala/aboutala/missionhistory /plan/strategic\%20plan\%202015\%20documents/2015_strategic_plan_1.pdf

Barack, L. (2006). Library gets Second Life. School Library Journal, 52(6), 26.

Bi-xia, D. E. N. G. (2010). On the innovation of services and harmonious library construction. Journal of Management 1, 26-35.

Buckland, A. \& Godfrey, K. (2008, August). Gimmick or groundbreaking? Canadian academic libraries using chat reference in multiuser virtual environments. Proceedings of the World Library and Information Congress, 74th IFLA General Council and Meeting. Retrieved October 31, 2008, from http://www.ifla.org//V/ifla74/papers/158-Buckland_Godfrey-en.pdf

Cheal, C. (2007). Second Life: Hype or hyperlearning. On the Horizon, 15(4), 204-210.

Huancheng, L., \& Miaolei, Z. (2011). The research of library innovation service under ubiquitous environment. In Uncertainty Reasoning and Knowledge

Engineering (URKE) International Conference on (Vol. 2, pp. 111-114). IEEE.

Marks, H. (2013). E-Portfolios: Demonstrating Professional Activities Online and Asserting What it Means to be a Librarian to Your Community and Profession. Journal of Electronic Resources Librarianship 25(1), 63-64.

Martell, C. (2003). The role of librarians in the twenty-first century. In M. A. Drake (Ed.), Encyclopedia of library and information science (pp. 2524-2536). New York: Marcel Dekker.

Online Computer Library Center, Inc. (OCLC). (2005). Perceptions of libraries and information resources. Dublin, OH: OCLC Inc. Retrieved March 27, 2008 from http://www.oclc.org/reports/pdfs/Percept_all.pdf

Stevanović, M., \& Crnogorac, V. (2011). Librarian and user in a digital environment: What has actually not changed?. Information science. Information science and Information Literacy Conference, Sibiu, Rumunjska, Croatia, April 14-15.

Taylor, T. L. (2006). Play between worlds: Exploring online game culture. Cambridge, MA: MIT Press.

Trueman, R. B., Peters, T., \& Bell, L. (2007). Get a Second Life! Libraries in virtual worlds. In R. S. Gordon, Information tomorrow: Reflections on technology and the future of public and academic libraries (pp. 159-71). Medford, NJ: Information Today.

Turkle, S. (1995). Life on the screen: Identity in the age of the Internet. New York: Simon and Schuster. 